\title{
ARTÍCULOS
}

\section{EL "LUGAR» DE LOS CAMPAMENTOS DE REFUGIADOS EN LA CONSIDERACIÓN ANTROPOLÓGICA}

\author{
THE PLACE OF REFUGEE CAMPS IN ANTHROPOLOGICAL CONSIDERATION
}

\author{
Juan Pablo Aris Escarcena ${ }^{1}$ \\ Universidad de Sevilla
}

Recibido: 16 de marzo de 2019; Aprobado: 20 de enero de 2021.

\begin{abstract}
Cómo citar este artículo / Citation: Aris Escarcena, Juan Pablo. 2021. "El «lugar» de los campamentos de refugiados en la consideración antropológica". Disparidades. Revista de Antropología 76(2): e027. doi: <https://doi.org/10.3989/dra.2021.027>.

RESUMEN: En su célebre obra «Los no lugares. Espacios del Anonimato.», el antropólogo francés Marc Augé define los campamentos de refugiados como no lugares (Augé 1998 [1992]). Sin cuestionar la validez de la categoría para definir los otros espacios característicos de la "sobremodernidad», analizaremos la aplicabilidad de la misma para los campamentos de refugiados sobre la base del trabajo de campo empírico en los campamentos existentes en varios contextos europeos actuales. Nuestras conclusiones contradicen esta propuesta teórica. En un momento histórico, llamado la "crisis de los refugiados en Europa», es necesaria la reflexión sobre la interpretación desde la antropología cultural de estos espacios.
\end{abstract}

PALABRAS CLAVE: Refugiados; Campamentos; No lugar; Europa; Apropiación cultural.

ABSTRACT: In his renowned book entitled "Non-places: Introduction to an Anthropology of Supermodernity", the French anthropologist Marc Augé defines refugee camps as Non-places (Augé 1995 [1992]). Without prejudice to the legitimacy of such conceptual category in the definition of different spaces peculiar to the "supermodernity", we will analyse the applicability of such conceptual category to refugee camps, on the basis of our empirical research in the existing camps in several European countries. Our conclusions reject this theoretical approach. At a singular moment in history, the so called "European refugee crisis», it is necessary to reflect upon the interpretation of these spaces from a cultural anthropological perspective.

KEYWORDS: Refugees; Camps; Non-Places; Europe; Cultural Appropiation.

Copyright: @ 2021 CSIC. Este es un artículo de acceso abierto distribuido bajo los términos de la licencia de uso y distribución Creative Commons Reconocimiento 4.0 Internacional (CC BY 4.0).

1 Correo electrónico: jparisescarcena@hotmail.com. ORCID iD: <https://orcid.org/0000-0002-2889-3168>. 


\section{INTRODUCCIÓN}

El antropólogo Marc Augé es uno de los más famosos antropólogos franceses de finales del siglo $X X$, y su obra "Los no lugares. Espacios del Anonimato. Una antropología de la sobremodernidad» es una de las más citadas en general y del propio autor en particular (Augé 1998 [1992]). En ella propone la categoría conceptual del no lugar, como la construcción socio-espacial propia de la sobremodernidad, actual período histórico y que ha sido definido por otros antropólogos como «modernidad desbordada» (Appadurai 1996), o «modernidad líquida» (Bauman 2003). Dentro de esta categoría conceptual, el autor engloba una serie de espacios que:

"Son tanto las instalaciones necesarias para la circulación acelerada de personas y bienes (vías rápidas, empalmes de rutas, aeropuertos) como los medios de trasporte mismos o los grandes centros comerciales, o también los campos de tránsito prologado donde se estacionan los refugiados del planeta». (1998: 41. El énfasis es añadido)

Durante nuestro trabajo de campo etnográfico en varios campamentos de refugiados en Europa, hemos llegado a cuestionar la aplicabilidad de esta construcción teórica como marco para la comprensión de las dinámicas socioculturales propias de estos espacios. ¿Son no lugares estos campamentos que se han multiplicado en la historia reciente? ¿La aplicación de esta categoría conceptual tiene potencial explicativo? ¿Qué aplicación heurística tiene? Con el objetivo de responder a estas cuestiones, es necesario realizar una revisión de esta construcción teórica que es refutada en este artículo a partir de nuestro propio análisis.

La metodología para esta investigación se basa en la revisión bibliográfica de $\mathrm{M}$. Augé así como de la literatura producida por otros autores desde la antropología y las ciencias sociales, que se cuestiona a partir de las evidencias etnográficas de nuestro propio trabajo de campo multisituado, desarrollado entre 2016 y 2019 a lo largo de distintos lugares de Europa. Los casos etnográficos proceden, en su mayoría, de los campamentos estudiados en Grecia (principalmente, el campamento de recepción oficial de Katsikas, en el noroeste de la Grecia continental) y en Francia (en la región del Nord, en la ruta migratoria que conecta el continente con Reino Unido). La aproximación etnográfica se ha basado en la observación participante en estos lugares a través de la colaboración estrecha con las distintas organizaciones de voluntarios que daban asistencia en estos lugares. Gracias a esta interacción cotidiana con las personas exiliadas hemos podido conocer el funcionamiento social de estos lugares. Debido a la enorme implicación emotiva de estas experiencias de vida, se ha primado la entrevista informal como técnica de investigación; a pesar de ello, se han registrado audiovisualmente más de 50 entrevistas, con trabajadoras, voluntarias y exiliadas. En este artículo, que tiene por objetivo una revisión conceptual, presentamos sólo una pequeña muestra de los testimonios y observaciones desarrolladas durante este trabajo etnográfico.

\section{LOS LUGARES Y LOS NO LUGARES}

Marc Augé ha realizado una reflexión profunda sobre las bases que permiten a la antropología alcanzar una comprensión de los procesos humanos (sociales y culturales) en el presente histórico, al que da el nombre de "sobremodernidad", caracterizándolo por el exceso (en el tiempo, en los espacios y en la individuación). La cuestión, sobre la que interroga a las dos grandes figuras de la historia de la antropología francesa, M. Mauss y C. Levi-Strauss, pasa a ser cómo esta tradición disciplinaria que se había construido sobre universos etnológicos nos puede permitir comprender un mundo marcado por la trasformación, por el exceso y el flujo.

La antropología clásica se había preocupado por perfilar universos de sentido, de reconocimiento: a estos universos simbólicos se los llamó cultura y se los presentó como sinónimos de la gente que los hacía existir, como los Bororó de Levi-Strauss. En una revisión crítica de estos procedimientos clásicos de la disciplina, de su construcción de las culturas como totalidades y la homogeneidad asumida en el interno de estas sociedades localizadas, el autor concluye:

\footnotetext{
«Esencializar cada cultura singular es ignorar a la vez su carácter intrínsecamente problemático, del que dan testimonio sin embargo en cada momento de sus reacciones ante las otras culturas o ante las sacudidas de la historia, y la complejidad de una trama social y de posiciones individuales que no pueden nunca deducir el 'texto' cultural. Pero no habría que ignorar la parte de la realidad que subyace en la fantasía nativa y en la ilusión etnológica: la organización del espacio y la constitución de lugares son, en el interior de un mismo grupo social, una de
} 
las apuestas y una de las modalidades de las prácticas colectivas e individuales. Las colectividades [...], como los individuos que se incorporan a ellas, tienen la necesidad simultáneamente de pensar la identidad compartida [...] El tratamiento del espacio es uno de los medios de esta empresa». (Augé 1998: 57)

Así, un lugar «puede definirse como lugar de identidad, relacional e histórico, (mientras que) un espacio que no puede definirse como espacio de identidad, ni como relacional ni como histórico definirá un no lugar» (Augé 1998: 83). Los lugares por tanto poseen tres características fundamentales: a) Son un lugar de identidad, b) Son relacionales, c) Son lugares históricos.

Los lugares antropológicos son entendidos como identificatorios en su relación con los universos simbólicos, es decir, con las construcciones socioculturales que permiten a un individuo tomar su identidad como parte de una colectividad ( $y$, al mismo tiempo, como miembro de un grupo particular de dicha comunidad y como persona diferenciada dentro de los mismos). Lo identificatorio del lugar viene dado de la capacidad de los miembros de una comunidad de hacerse valer, de reconocerse y ser reconocidos, en tanto capaces (o sabedores de no ser capaces) de emplear los códigos que estructuran la lógica interna que lo vertebra. Llegado el punto, «el dispositivo espacial es a la vez lo que expresa la identidad del grupo [...] y es lo que el grupo debe defender contra las amenazas externas e internas para que el lenguaje de la identidad conserve su sentido» (Augé 1998: 51). La demarcación del territorio por las culturas y grupos humanos, la apropiación cultural del espacio, es una vía de doble sentido y define la identidad colectiva y particular.

Ahora, en tanto que toda identidad es colectiva, la misma sólo puede definirse de manera relacional. Las colectividades humanas se definen de manera relacional al interno y al externo de sí mismas, incluyendo a través de la construcción del lugar. La relacionalidad la entiende en un sentido amplio, refiriendo a los sujetos, pero también a los objetos y a la propia construcción cultural del entorno. Esta característica sirve de puente conector entre las otras dos características fundamentales del lugar antropológico, puesto que pone de manifiesto la no inmutabilidad de lo identitario del lugar $y$, por tanto, reconduce a su dimensión histórica como fuente de su validez y existencia misma.

Lo histórico de un lugar hace referencia a esta doble dimensión, a la conexión diacrónica de las identida- des relacionales con el lugar con el que se representan y la historia de la comunidad que queda representada en el mismo. En el primer sentido, se refiere a la continuidad temporal de una dinámica relacional que define elementos identitarios e identificativos. En el segundo sentido, poder percibir elementos de esta identidad colectiva en la configuración espacial es un resultado fruto de las dinámicas socioculturales de acción (voluntaria y no) sobre el territorio por parte de los colectivos. Este segundo punto es el más complejo de resolver, pues incluye de una manera no resuelta la construcción de una historia por la acción social y la construcción de una Historia por la acción culturalmente reflexiva. En cualquier caso, para $\mathrm{M}$. Augé un lugar antropológico está marcado por estas dimensiones históricas (diacronía, historia e Historia).

Por último, estas tres características conceptuales de la configuración social de los lugares antropológicos es puesta en relación por el autor con tres formas geométricas y tres respectivas series espaciales: la línea (los itinerarios, ejes y caminos), la intersección de la línea (las encrucijadas) y el punto de intersección de la línea (los centros).

La definición del no lugar se realiza en referencia a lo anterior. El no lugar de la sobremodernidad se presenta como aquello que no es: no es identificatorio ni relacional, sino sólo a través de la denominada «soledad contractual» que los caracteriza y que refuerza el exceso individualista; ni es histórico, pues no fija relaciones estables ni recrea la Historia, a menos que sirve para convertirla en reclamo para los flujos de mercancías. Son los espacios que caracterizan un «mundo así prometido a la individualidad solitaria, a lo provisional y a lo efímero, al pasaje, [...]» (Augé 1998: 84). En otro punto, el M. Augé (1998: 98) señala:

"Se ve claramente que por no lugar designamos dos realidades complementarias pero distintas: los espacios constituidos con relación a ciertos fines (transporte, comercio, ocio) y la relación que los individuos mantienen con esos espacios. [...] cómo los lugares antropológicos crean lo social orgánico, los no lugares crean la contractualidad solitaria».

En un último intento de definición que supere la antinomia establecida, apunta que «el lugar y el no lugar son más bien polaridades falsas: son palimpsestos donde se reinscribe sin cesar el juego intrincado de la identidad y la relación» y acompaña esta definición del no lugar como concepto de una enumeración de 
los espacios «reales» (autopistas, cadenas hoteleras, supermercados) que conforman esta territorialidad.

Los campamentos de refugiados son considerados por el autor como parte de los no lugares que caracterizan la sobremodernidad. A pesar de esta inclusión hay pocas referencias a los campamentos de refugiados a lo largo de la obra y nunca se emplean descripciones o ejemplos de los mismos para caracterizar y hacer explícita la definición conceptual del no lugar, a diferencia de los otros elementos englobados como hemos visto en las definiciones anteriores; sólo dos menciones se realizan a los "campos de refugiados» (Augé 1998: 41 y 83). Sin embargo, la teorización de los campamentos de refugiados como no lugares ha tenido un impacto muy significativo en el desarrollo de la teoría social.

\section{LOS CAMPAMENTOS DE REFUGIADOS COMO NO LUGARES Y SUS LIMITACIONES EPISTEMOLÓGICAS}

La definición de los campamentos de refugiados como no lugares que realizó Augé en 1992 ha tenido una trascendencia enorme, mucho más allá de lo que es reconocido. Esta definición se establece en plena descomposición del "mundo de bloques», a penas terminado el «corto S. XX» (Hobsbawm 1994), cuando los campamentos son una realidad que se multiplicaba de manera acelerada en el mundo. El mismo año que fue publicada la obra de M. Augé nacía en Kenia uno de los campamentos más grandes del mundo: Dadaab. Basándose en su análisis de este mismo campamento, M. Agier (2001) inició su propia interpretación de los campamentos de refugiados que recogía y ampliaba la conceptualización de Augé: «Construido primero como un desierto genuino o como un no lugar, ¿puede el campo de refugiados convertirse en una ciudad en el sentido de un espacio de sociabilidad urbana, un 'urbi', o incluso en el sentido de un espacio político, una 'polis'? ¿O por qué no puede?» (2001: 130). La conclusión a la que arriba Agier, refuerza la novedad y la particularidad del campamento de refugiados como no lugar: «El campamento, incluso cuando se estabiliza, sigue siendo una ciudad desnuda» (2001: 136).

La posición de M. Agier, refleja la tendencia predominante en la interpretación desde las ciencias sociales en el análisis de los campamentos de refugiados como lo que no es, y las formas de poder que se ejer- cen sobre las personas que son destinadas allí como el poder de la exclusión radical. Una de las obras que consolidó la preponderancia de estos elementos teóricos fue "Homo Sacer: el poder soberano y la nuda vida» de G. Agamben (1998). La idea central de la obra, simplificando, podría resumirse por el análisis de las formas de detención y exclusión de los migrantes como las expresiones de un poder soberano no limitado y que tenía la capacidad de reducir a la "humanidad desnuda» a aquellos sobre los que ejercía su gobierno, el homo sacer, quien no puede ser sacrificado, pero es expulsado de la comunidad y su muerte no es imputable. vincula la tradición occidental del establecimiento de mecanismos para la exclusión radical de la comunidad política y social propios de la tradición occidental (que el retrae hasta el derecho romano) con los campos y campamentos, como mecanismos de producción de esa nuda vida o vida desnuda. El filósofo italiano vincula los mecanismos propios del lager con los mecanismos de los nuevos campamentos que surgen en el mundo actual, llegando a establecer el campo como destino de las formas de gobierno contemporánea del estado-nación: «Desde esta perspectiva, el campo, como espacio biopolítico puro, absoluto e intransitable, aparecerá como el paradigma oculto del espacio político de la modernidad» (1998: 72).

La perspectiva de la vida desnuda y del no lugar se complementan mutuamente y han servido de base a una panoplia de análisis sociales, que han ido más allá del análisis del campamento, pasando al análisis de las personas que son recluidas en los mismos y de las políticas que vertebran el gobierno que se les impone. Muchas de las teorías más relevantes de principio del S. XX comparte esta influencia de Agamben y Augé: la construcción de las «no-personas» (Dal Lago 2004), la construcción de la animalidad como base del poder soberano o "zoopolítica» (Derrida 2010), o la provocadora conceptualización de $A$. Mbembe, que centrándose en las mortales consecuencias del gobierno de las migraciones las ha denominado «necropolítica» (2003). La identidad de los refugiados es dejar de ser; pasan a definirse, como el no lugar, por lo que no es. En un pasaje, $Z$. Bauman señala que:

\footnotetext{
"Al haber abandonado su medio anterior, o al haber sido expulsados de él, los refugiados tienden a ser despojados de las identidades que ese medio definía, sostenía y reproducía. En términos sociales, son 'zombis'. [...]. A los fines prácticos, los refugia-
} 
dos han sido arrojados al estadio intermedio del pasaje en tres etapas de Van Gennep y Victor Turner». (Bauman 2008: 148 - 149)

Esta tendencia teórica surgió vinculada a un importante impulso de denuncia, en un momento histórico en el que los migrantes y refugiados estaban cada vez más presentes en el discurso político y mediático, en el que las fronteras eran crecientemente el escenario del espectáculo de la exclusión radical (De Genova 2013) y la presencia de los migrantes era construida como una amenaza y una "carga» económica y social. Es parte del proceso histórico en el que se estaba configurando las dinámicas de gobierno que se han hecho dominantes, en la cual las políticas securitarias y humanitarias definen los procesos de inclusión y exclusión de las personas migrantes, a partir de una jerarquización jurídico-administrativa de las mismas (Düvell 2011) y que se relaciona con otras formas de categorización de origen colonial (Barou 2014). En este contexto, el acento puesto en las consecuencias más inhumanas de las prácticas de gobierno que se estaban consolidando era un desafío desde el análisis social. Sin embargo, contribuyó a consolidar la imaginación social de las migraciones a partir de una segmentación de los colectivos basado en su naturaleza jurídica: estudios de refugiados, estudios de migraciones, estudios de movilidad (vinculados a las migraciones privilegiadas y representadas positivamente, por ejemplo: Recchi (2015)); cada vez más distantes entre sí y más autorreferenciales.

En paralelo, y partiendo de un acuerdo parcial con las formulaciones dominantes, ciertas autoras comienzan a interpretar las dinámicas de gobierno desde una óptica diversa: se centran en los elementos productivos. A diferencia de la teoría del no lugar y de la excepcionalidad como efecto del poder, se empieza a cuestionar el ejercicio del gobierno como la creación de víctimas y se cambia el foco de análisis de las prácticas más violentas a las dinámicas de la cotidianeidad de los lugares humanitarios. L. Malkki $(1992,1994,1996$ y 1997) puede considerarse una de las pioneras en la reinterpretación de los lugares de exilio como productores de víctimas, como los lugares de producción del sujeto de gobierno humanitario desde la tradición antropológica. El desafío a la conceptualización del no lugar y de la exclusión soberana comenzó a plantearse desde múltiples frentes. F. Rahola (2003, 2006 y 2007) realiza una revisión historiográfica y sociológica de los orígenes del campa- mento de refugiados, que como el muestra antecede a la propia definición de las personas que residen en estos lugares a través de la categoría jurídico administrativa de refugiado. En su genealogía de los campos, el autor italiano recupera las teorías del homo sacer y las pone en relación con el corpus teórico elaborado por $\mathrm{H}$. Arendt para trazar las conexiones y desconexiones históricas del campamento como técnica de gobierno, a través del nexo entre su pasado colonial y su reintroducción en Europa. Fue W. Walters (2006, 2011 y 2015) quien acuñó, desde la geografía humana, el concepto fronteras humanitarias, que se refería no sólo a la enorme relevancia que las formas de gobierno humanitario estaban adquiriendo, sino a la multiplicación de las fronteras a través de las instituciones humanitarias que se desarrollaban en toda la geografía europea (y no sólo). La multiplicidad de las fronteras se ha convertido en un objeto de estudio central, ya que:

\footnotetext{
"Nos encontramos no solo frente a una multiplicación de diferentes tipos de fronteras sino también ante un resurgimiento de la profunda heterogeneidad del campo semántico de la frontera. Los límites simbólicos, lingüísticos, culturales y urbanos ya no son articulados de un modo estable por la frontera geopolítica. Por el contrario, se superponen, se conectan y se desconectan en modos, frecuentemente, impredecibles, contribuyendo a modelar nuevas formas de dominación y explotación». (Mezzadra y Neilson 2017: 11).
}

En esta reconfiguración de las formas de dominación a través de las fronteras, los campamentos pasan a tener una importancia central tanto en su desarrollo como en la reflexión antropológica.

Desde 2011 y decididamente desde 2015, los grandes éxodos del "gran verano de las migraciones» (Hess et al. 2016; Hess y Kasparek 2017) han recibido la atención política y mediática y se han popularizado sus representaciones como crisis, primero de los refugiados, después migratoria. Las dinámicas de gobierno durante este período han consolidado la trascendencia del campamento como técnica de gobierno y su relevancia en el universo simbólico europeo. Ha sido en este momento histórico cuando se ha comenzado a producir una ruptura con la conceptualización de la excepcionalidad y del campamento como no lugar. Múltiples autoras han cuestionado las dinámicas de gobierno que se basan en el campamento y el humanitarismo. Miriam Ticktin (2005, 2014 y 2016) es 
una de las antropólogas que ha desarrollado la crítica del humanitarismo con mayor acierto, pero a ella se suman otros muchos como K. Rygiel (2011 y 2016), IIcan y Rygiel (2015), M. Stierl (2016 y 2018), o D. Fassin $(2007)^{2}$. Una crítica que afecta también al propio quehacer de los etnógrafos y antropólogos que participan en la vida de estos lugares de gobierno humanitario (Ben-Yehoyada et al. 2020; Cabot 2019a y 2019b) y que debe asumir «la carga de la complicidad epistemológica con los mismos fenómenos que tratan de examinar» (Rozakou 2019: 78).

Sin embargo, en la mayoría de los casos la atención que se ha prestado a los campamentos como lugar en sí ha sido muy reducida. En este artículo me esfuerzo por demostrar que los campamentos deben ser considerados como lugares antropológicos y el potencial epistemológico en analizarlos como tales. A través del análisis etnográfico de los campamentos puede mostrarse como incluso los campamentos que consideramos más efímeros, por su reducido tamaño o por su corta duración, están conectados con la reproducción social de distintos colectivos de actores entre lo que destacan las personas migrantes y exiliadas a las que se niega la legitimidad de ser y estar en nuestras sociedades. Como afirma E. Sandri (2018: 6):

"En ciertos ámbitos, los campamentos de refugiados, incluida la Jungla, han revelado la capacidad de construir un tipo alternativo de espacio sociopolítico, basado en la coexistencia de los refugiados y otros actores en el espacio híbrido del campamento, y debe entenderse más allá de la noción de vida desnuda (aquí incluye una referencia directa a Agamben). Así pues, [...] el campamento no se examina aquí como un lugar vacío de la agencia de los refugiados, sino más bien como un sitio liminal donde se encuentran diferentes subjetividades».

La autora recupera así la liminalidad señalada por Bauman, pero la conecta con una dimensión productiva. Los campamentos, como lugares de gobierno humanitario, son primero lugares de producción de identidades en el que las personas que los viven definen en negociación su inclusión. La inclusión es ciertamente diferencial y está marcada por una jerar-

2 La evolución de la reflexión y la teorización de D. Fassin es muy significativa de las transformaciones en el análisis social desde el mundo francófono. En sus primeros análisis, el humanitarismo se vincula a la acción exterior, y progresivamente su atención ha ido centrándose en las lógicas y prácticas del humanitarismo en Europa. quización, pero es sólo en su vida localizada e históricamente situada que los campamentos pueden ser aprehendidos. El análisis de la realidad de las personas migrantes que viven en estos lugares puede realizarse desde la antropología de esta manera, etnografiando el proceso por el cual las personas construyen su estatus social. Entender los campamentos como lugares nos permite estudiar los procesos relacionales profundos que vertebran la historia no sólo de los migrantes sino de las sociedades europeas.

En los campamentos se pone en juego un proceso de definición del estatus social de los migrantes como un proceso simbólico, que tiene como marco de referencia las categorías jurídico-administrativas con las que se define su legitimidad de permanecer o su criminalización por el mero hecho de ser y estar. Si este artículo se refiere a los "campamentos» ${ }^{3}$ es por mantener la terminología empleada por M. Augé. En francés, el uso de la palabra camp tiene connotaciones particulares en el análisis de las dinámicas de gobierno que exceden la palabra "campamento», por la que la traducción de la obra de Margarita Mizraji ha optado. Sin embargo, creo que esta traducción es acertada en tanto que el término «campo» en castellano nos dirige, por sus reminiscencias, a los lager, campos de exterminio. Uno de los objetivos de este artículo es justamente discutir el valor epistemológico de las teorías que analizan los campamentos contemporáneos a partir de una vinculación teórica con los espacios de excepcionalidad soberana y de nuda vida. Las realidades cotidianas de las personas que viven en los lugares que llamamos campamentos de refugiados se vincula al proceso de definición de su legitimidad como sujeto social y al crecimiento de los ámbitos de gobierno securitario y humanitario. Como se desarrolla a través de los casos etnográfico, la definición simbólica que se da en estos lugares sobrepasa la categorización de las definiciones jurídico-administrativas ${ }^{4}$. En el próximo apartado, argumentaré cuales

3 Agradezco a las revisoras sus comentarios en relación al uso de este término.

4 En mi producción científica he intentado abandonar el uso del término refugiado por sus connotaciones vinculadas a una categoría jurídico-administrativas y a una imaginación humanitarista de su identidad, dos ámbitos íntimamente relacionados con la segmentación y jerarquización que se busca imponer entre las personas desplazadas de forma más o menos voluntaria o forzada. Por ello he empleado como alternativa el término exiliados, que comporta además la ventaja de volver a conectar políticamente los procesos de desplazamiento y migración. 
son los elementos que nos permiten analizar distintos campamentos como lugares y que ventajas ofrece esta consideración para el análisis etnográfico.

\section{EL CAMPAMENTO COMO LUGAR: ELEMENTOS IDENTITARIOS, PROCESOS RELACIONALES E HISTORIA}

En la construcción de los campamentos se plasman elementos identitarios tanto de las comunidades de acogida como de las comunidades de refugiados que pasan a habitarlos. la delimitación, el posicionamiento y la propia existencia de un campamento en una localidad determinada parten de un posicionamiento de la colectividad (y/o de sus dirigentes) frente a la situación de las personas migrantes. En la (antigua) región administrativa de Nord-Pas-de-Calais, encontramos varios ejemplos de esta impronta de la identidad de la comunidad en el establecimiento y en la destrucción de varios campamentos a lo largo de la reciente historia. El primer campamento en la región nació en torno al centro de la Cruz Roja en Sangatte (Schwenken 2014). Este primer campamento tuvo una marca importante en la historia del territorio y fue simbólicamente muy relevante. A nivel político, Sangatte era, antes de la existencia del campamento, un punto clave que representaba la cooperación entre Francia y Reino Unido en el control migratorio y fronterizo, formalizada en el Protocolo de Sangatte. La mayor revisión de este protocolo y actual fuente de referencia a nivel jurídico es el Tratado de Touquet; una de las clausulas principales en las negociaciones de dicho tratado fue la destrucción del campamento de Sangatte, lo que implicó también el desmantelamiento de las instalaciones humanitarias de la Cruz Roja.

El campamento más conocido a nivel público y mediático, el campamento de "la Lande» conocido como la gran «Jungla» de Calais, nació como un lugar auto-establecido a partir de un espacio definido por el gobierno francés en la periferia de la ciudad de Calais, donde se estableció un centro de día. Es interesante señalar un elemento respecto al carácter identitario de este lugar: el centro en torno al cual se originó recibía el nombre de Jules Ferry. Esto puede no ser más que una anécdota, pero una anécdota muy significativa. El centro era un centro de día, enfocado principalmente a la asistencia humanitaria y gestionado por una ONG francesa La vie Actif, que mantenía el nombre de un antiguo lugar para campamentos de verano infantiles, nombrado Jules Ferry en memoria de uno de los grandes promotores de la escuela pública laica y universal en Francia. Sin embargo, se olvidaba la otra "gran aportación» que había realizado Jules Ferry: su ferviente defensa del proyecto colonial francés y su misión civilizadora. La ironía o el cinismo de la historia ha querido que este nombre fuera el que se le dio (o el que se mantuvo por herencia) al centro de día que está en los orígenes de la gran Jungla de Calais, el lugar de frontera más célebremente infame y nuevo símbolo de los procesos de exclusión y violencia hacia los exiliados. En una nota al pie de página de su ensayo "Las fronteras de Europa», Étienne Balibar (2002: 102) señala «A menudo se plantea la pregunta sobre qué constituye el vínculo interno, que es históricamente evidente pero teóricamente enigmático, entre educación francesa y colonización, ambos simbolizados en el nombre de Jules Ferry. Yo creo que el vínculo pasa por la institución religiosa de la frontera».

Si su construcción expresa elementos identitarios, también lo hace su destrucción, como procesos cargados simbólicamente y que expresan los límites negativos de la pertenencia a la comunidad. El centro de Sangatte y la Jungla de Calais fueron destruidos en 2003 y 2016 respectivamente, marcando el inicio de procesos de expulsión de los refugiados estas regiones (Aris Escarcena 2019; Aris Escarcena y Da Silva 2019), procesos marcados por una gran violencia tanto física como simbólica hacia los «refugiados», pero igualmente hacia los lugares: fueron completamente destruidos utilizando palas excavadoras y otros tipos de maquinaria pesada; en el terreno de la Jungla de Calais, incluso la vegetación característica de la zona fue arrasada.

En este sentido, el análisis de la vida de estos campamentos como lugares antropológicos nos permite profundizar en las conexiones que mantienen con procesos socioculturales mucho más amplios y diversos que la excepcionalidad y la exclusión radical o la producción de la nuda vida. Un cambio de enfoque es necesario para poder analizar los vínculos con la realidad social a nivel de las comunidades (locales y nacionales) y con los procesos de imaginación social de esta realidad por parte de las personas. En esta misma región del norte de Francia, el campamento de la Linière, en Grande-Synthe ${ }^{5}$, se contruyó como un lugar a partir de la recreación de una identidad

5 Donde realicé trabajo de campo en marzo y abril de 2017. 
social diferencial por parte de los habitantes de esta ciudad y de sus representantes locales. Tras la destrucción violenta de la Jungla de Calais, el gobierno de la ciudad de Grande-Synthe anunció la creación un campamento de refugiados ${ }^{6}$.

Por otro lado, existen múltiples elementos identificativos e identitarios que se materializan en la configuración interna del campamento. Estos muestran la propia diversidad interna de los conjuntos poblacionales que se representan como homogéneos bajo el rótulo de refugiados. Desde la distribución espacial, a las modalidades de aprovechamiento de las viviendas, al establecimiento de símbolos identitarios como símbolos políticos o religiosos, los diversos grupos presentes participan en un proceso de apropiación cultural del espacio. En el campamento de la Linière, las comunidades étnico-nacionales mayoritarias presentes eran la iraquí y la afgana, aunque también existía una comunidad iraní de cierta importancia. El contraste aumentaba entre ambos grupos, ya que la inmensa mayoría de los iraquíes e iraníes eran étnicamente kurdos. El campamento estaba dividido físicamente en dos mitades por el paso de un desagüe de la carretera a través del campamento, y que sólo podía cruzarse por un angosto camino. Esta división preexistente se llenó de simbolismo, al ocupar la población kurda la mitad más alejada de la entrada, quedando la población árabe (en su mayoría afganos) en la otra mitad. Las pequeñas viviendas prefabricadas - cuadrados de dos metros de lado delimitados por paredes de madera contrachapada y un techo de chapa metálica - se convirtieron en un expositor perfecto para los símbolos de identidad de estas comunidades, por ejemplo pintando en las paredes de sus viviendas la bandera del Kurdistán, el deseado estado independiente formado por los «kurdistanes» ${ }^{7}$ de Turquía, Siria, Irak e Irán. En varias de las

6 Este caso es ilustrativo de mi crítica al uso del término refugiado, puesto que las personas que vivían en las instalaciones de Grande-Synthe no eran «refugiadas» más que potencialmente, pues no habían recibido el estatus administrativo como refugiadas por parte del estado francés ni de ningún otro de la Unión Europea. De hecho, muchas de ellas habían terminado viviendo en este lugar al ser rechazadas sus solicitudes de protección internacional por Francia u otros estados europeos (especialmente Alemania), con el objetivo de continuar su proyecto migratorio en dirección a Reino Unido.

7 Por kurdistanes nos referimos a los territorios poblados mayoritariamente por este grupo étnico, ya tengan una delimitación territorial y un reconocimiento administrativo y político por parte del estado-nación al que pertenecen en la actualidad o no. Remitimos a la opción cita- viviendas más cercanas al desagüe se exhibía pinturas esquemáticas, compuestas de líneas monocromas, pero de altísima calidad y similitud, que representaban los relieves de los palacios asirios y persas de Irak; entre ellos, destacaba una reproducción en pintura del relieve del «genio alado dando la bendición» del palacio de Sargón II, Dur-Sharrukin, cuyo original se encuentra también en territorio francés, en el museo del Louvre. Esta división del espacio hacia presente en el campamento los elementos identitarios, que servían para marcar las fronteras étnicas entre las comunidades al interno del mismo.

La trascendencia de estas dinámicas de relaciones interétnicas no sólo invalida la interpretación de los campamentos como no lugares de contractualidad solitaria, sino que nos permite pensar más allá de la oposición estéril entre agencia y estructura para profundizar en los procesos sociales en los que se negocia y define la identidad de las personas que viven en estos lugares. En la imaginación de la «crisis de los refugiados» una cuestión central ha sido la vinculación de los distintos grupos étnicos con la imagen de «los refugiados» en Europa, que principalmente se ha referido a población siria que huye del conflicto; esto ha marcado una clara diferenciación entre la población de estados del Próximo Oriente y el resto de migrantes. Esto implicó una exclusión y marginalidad en base a la diferencia fenotípica: el «refugiado» era fenotípicamente «árabe» (si acaso esto existe) o, de una manera más tajante, no eran «refugiadas» las personas fenotípicamente negras. La negritud jugó un papel central en el tratamiento recibido por los migrantes en esta región de Francia. El modo relacional vinculado a la estigmatización de la población negra en Francia (Barou 2014) nos podría retrotraer hasta las obras de Frank Fanon. El modelo no es el mismo, y se han producido mutaciones en él, relacionadas con las nuevas representaciones y la nueva coyuntura sociohistórica; sin embargo, la negritud sigue funcionando como un estigma. Los comentarios de un joven palestino que descansaba en un centro de día junto a los colectivos de personas negras, si bien no son estadísticamente representativos si son muy significativos de la situación:

"Yo de noche no voy con ellos nunca, menos si voy a intentar subir a algún camión. Si voy yo solo me echan o me detienen y paso una noche en la comisaria, pero bien. Si voy con ellos y nos

da de R. Stavenhagen para profundizar en la compleja situación de estos territorios en el marco político regional, que se ha hecho aún más compleja por los distintos conflictos bélicos que afectan a la región. 
encuentran nos pegan, seguro. A mí la primera vez me quede quieto mientras todos corrían e incluso así el policía me pegó y me echó gas lacrimógeno [...]. No sabía que tenía que correr. Cuando he ido sólo nunca me había pasado eso».

En muchas ocasiones, modelos opresivos de relaciones interétnicas (Vertovec y Cohen 1999) son el origen de los desplazamientos de las personas que buscan en el exilio la protección internacional contra la persecución y el genocidio, cómo es el caso de los Yazidíes perseguidos por el Daesh o de los Rohingya perseguidos en Myanmar, en el sudeste asiático. En mi trabajo etnográfico he analizado la importancia de los elementos identitarios en la configuración espacial y en la aparición de elementos identificativos de las comunidades kurdas en dos campamentos contemporáneos muy distantes entre sí, el campamento de refugiados de la Linière en Grande-Synthe (Francia) y el campamento de recepción oficial en Katsikas (Grecia). Esto hace referencia directa a modelos relacionales que se dan dentro del campamento, tanto intraétnicos como interétnicos, que son precedentes al establecimiento de las personas exiliadas en estos lugares, y que se resignifican en el establecimiento y consolidación de los campamentos. El patrón de asentamiento espacial de las poblaciones kurdas dentro de los campamentos de refugiados que pude observar, en los dos casos relatados, no era casual: se establecieron separados de la entrada de los campamentos, lejos de los puestos de control de las autoridades, oficiales (militares o burocráticos) y no oficiales (de las distintas organizaciones y ONGs), fruto de la heredada suspicacia de los kurdos frente a los «burócratas a pie de calle» y los militares de los estados de donde procedían, donde la población kurda es una minoría étnica sobre la cual pesan medidas más o menos punitivas y represivas, y se realiza un mayor o menor proselitismo étnico-nacional (Stavenhagen 2000).

En ambos campamentos se produjeron también episodios de enfrentamiento violento entre miembros de las distintas comunidades étnicas. En Grande-Synthe, la noche del 10 al 11 de abril de 2017 el campamento tuvo que ser evacuado a causa de un fuego que arrasó gran parte de las viviendas de madera prefabricadas. El incendio fue resultado de una escalada de violencia entre un grupo de hombres jóvenes kurdos-iraquíes y afganos, que comenzó como una pelea provocada por la molestia que un grupo causó al otro jugando al fútbol en mitad del camino central del campamento. Tras la destrucción del campamento, los colectivos étnicos se organizaron de forma separada y buscaron destinos diferentes: los kurdos abandonaron la ciudad, mientras que los árabes fueron acogidos inicialmente en las instalaciones del polideportivo municipal. En Katsikas, un enfrentamiento semejante entre grupos de jóvenes a finales de junio de 2016 provocó que se realizaran una serie de amenazas (a través de pintadas en las tiendas y en las letrinas de ese sector del campamento) contra el colectivo Yazidí (kurdos). De manera colectiva, decidieron que, para evitar potenciales enfrentamientos, abandonarían el campamento; a la mañana siguiente unas ciento cincuenta personas (aproximadamente) abandonaron el lugar. Estas relaciones conflictivas derivan de una tensión interétnica previa a la situación de exilio, que en ciertas ocasiones se ven intensificadas por la tensión psicológica y social de la vida en las precarias condiciones que implica la cotidianeidad en los campamentos de refugiados.

La constitución de un nuevo lugar antropológico como son los campamentos puede dar como resultado la intensificación de una relación conflictiva pero también puede hacerla desaparecer. En ambos casos he podido observar la formación de grupos interétnicos de apoyo mutuo y convivencia, formados principalmente por hombres jóvenes que viajaban solos. En ambas situaciones hubo jóvenes que mantuvieron el contacto a pesar de provenir de grupos étnicos distintos. En Grande-Synthe un joven kurdo, tras la destrucción del campamento, me lo explicaba: «yo tengo varios amigos que son árabes. Eran mis amigos porque eran personas educadas, habían estudiado cómo yo y son personas buenas... pero después de esto ya no los voy a ver más, ya no. Estoy triste porque no es culpa nuestra». En Katsikas, tras los episodios de violencia y con el abandono en conjunto de los yazidíes los voluntarios de las ONG presentes en el terreno de manera cotidiana entraron en pánico cuando un conocido joven yazidí, que colaboraba con las actividades de las organizaciones como intérprete, parecía haber desaparecido durante todo un día. Al día siguiente, con total naturalidad, el joven pasó a saludar a los voluntarios y a decirles que se iba del campamento. Él había pasado la noche en la tienda de sus amigos árabes para despedirse de sus amigos antes de irse.

En ambos campamentos, cuando se han producido protestas políticas por la situación en la que se encontraban, todos los residentes del campamento han participado de las mismas sin mayor conflicto. En 
Katsikas, a mediados de abril de 2016, las personas exiliadas que vivían en el campamento realizaron una protesta conjunta donde todos participaron y que tenía el objetivo simbólico de cortar la carretera igual que su ruta migratoria había sido cortada; la intervención violenta de la policía griega para disolver la concentración supuso nuevos episodios de protesta (en el interior del campamento) en una muestra coordinada entre todos los colectivos presentes. Esto muestra la entidad propia que alcanzan los campamentos como lugares antropológicos donde, en la propia reproducción de las mismas, se redefinen las dinámicas relacionales entre grupos.

En la redefinición de las dinámicas relacionales, los campamentos en tanto lugares de vida de comunidades humanas, que además muchas veces ven limitada su movilidad al mismo o sus entornos, alcanzan en su propio desarrollo las características esenciales de la historicidad de los lugares antropológicos: tienen un desarrollo histórico propio (tienen historia), y son fruto y productores de Historia ${ }^{8}$ en su mayor sentido. La profesora Liisa Malkki ha teorizado sobre la construcción de los refugiados como sujetos del gobierno humanitario y sobre cómo se desarrolla una invalidación de su capacidad como sujeto político, como sujetos de la Historia en el sentido de actores con potencialidad y legitimidad para construir el relato sobre el proceso que los ha llevado al exilio (Malkki 1996). Esta reificación, en el profundo sentido que le asigna en su revisión sobre este concepto filosófico A. Honneth (2008), la falta del reconocimiento de las potencialidades como sujetos, implica una "deshistorización» de los refugiados cuya identidad como exiliados políticos queda suplantada por un estatus de humanidad universal, tan abstracta como vacía de contenido. El peligro de esto, para esta autora, es el silenciamiento de sus voces y su expulsión del campo político de negociación al final del conflicto o frente al régimen político que ha provocado su desplazamiento. Esta «neutralización» se realiza a través de una intervención humanitaria que parece resultar «inevitable», debido a las terribles circunstancias de las que escapan y que encuentran las personas exiliadas. Así, en todo caso, lo que existe sería una pretensión construida por el modelo de gobierno humanitario de "deshistorizar» los campamentos en tanto que se «deshistoriza» a los

8 Cómo los episodios funestos de los campamentos de refugiados palestinos de Sabra y Chatila (1982) muestran de manera tan trágica como contundente. "refugiados» y se los convierte en el «hombre desnudo" de G. Agambem, en las "familias universales» de $R$. Barthes, en sujetos no autorizados sino en víctimas mudas sujetas a la buena voluntad de un tipo de humanismo muy particular.

La historia en un campamento de refugiados, en tanto que proceso de desarrollo diacrónico de las poblaciones y los espacios, es una realidad innegable de estos lugares. La Historia, como construcción cultural y reconstrucción de la historia de los pueblos, como objeto de un saber experto y al mismo tiempo como campo de disputa social, está vinculada de manera compleja con los campamentos de refugiados. Señalé al inicio de este punto la interpretación de la profesora L. Malkki sobre la deshistorización que la intervención humanitaria ejerce sobre los refugiados. Sin embargo, cómo señalaba $M$. Augé al referirse a las características de los lugares antropológicos, la plasmación de la identidad en la construcción espacial es una de las principales vías que recorren los colectivos humanos. En un mundo en el que los refugiados están perdiendo o han perdido, entre tantas cosas materiales e inmateriales, la voz como actores políticos legitimados en la lucha por la Historia, el esfuerzo de los refugiados por hacer visibles sus signos identitarios se realiza sobre la materialidad de estos lugares. Uno de los elementos a los que $M$. Augé otorga una importancia destacada en la concreción real (física) de los lugares antropológicos es al "Monumento» en relación directa con su función de «instrumento de recuerdo/ de la memoria ${ }^{9}$, de donde proviene etimológicamente como nos recuerda el autor. "Sin ilusión monumental, a los ojos de los vivos la historia no sería sino una abstracción. La especie social está poblada de monumentos» (Augé 1998: 65). La existencia de monumentos en los campamentos de refugiados es una manifestación física de su entidad como lugares antropológicos, esas construcciones materiales y simbólicas particulares a través de las que se expresa para sí y en sí las comunidades culturales que los clásicos individuaban llamándolas culturas.

En la gran Jungla de Calais, antes de su desmantelamiento, se construyó una Iglesia y una Mezquita, y también se construyó una galería de arte, que recibió el nombre de Galería "Maxim le Forestier», en ho-

9 La palabra monumento proviene de la raíz del verbo monere (advertir, recordar) y del sufijo instrumental mentum. 
nor al célebre músico francés quien adquirió la «casa azul» (como el título de su famosa canción) del artista mauritano Alpha, obra central de la galería de arte mientas existió el campamento. En Grande-Synthe, las ya mencionadas pinturas que decoraban varias casas representaban, en el interior del campamento de refugiados de La Linière, los elementos monumentales del período de mayor esplendor de la civilización asiria, patrimonio cultural y simbólico de Irak, y una de las joyas expuesta en el Louvre. En Norrent-Fontes, en la misma región de Nord-Pas-de-Calais, se encontraba el campamento de refugiados que más tiempo llevaba en activo en la región, el cual nunca había sido desmantelado por las autoridades gracias al apoyo y sostén de la organización Terre d'Errance y de la comunidad local de este pueblo. Venido a menos por varias razones, en el campamento había menos de dos centenas de personas, pero se podía seguir visitando la mezquita erigida y la pequeña iglesia. En la entrada de este campamento, una gran placa conmemorativa presentaba la cara sonriente de un joven muchacho en la que se podía leer:

«En recuerdo de Mohammed Elsarag, 25 años,exiliado, víctima de las políticas migratorias, golpeado hasta morir por traficantes, 18 de Octubre de 2016».

Estos monumentos son una expresión de la vinculación con la Historia de unos lugares, los campamentos de refugiados, que como nos recuerda la efigie de $\mathrm{M}$. Elsarag son fruto de la nuestra Historia política más reciente. No puede explicarse la existencia de estos campamentos sino es considerándolos resultado de profundos procesos históricos que nos vinculan. Puede que la estabilidad de los campamentos sea relativa. Sin embargo, su carácter efímero en un territorio localizado no invalida su carácter histórico. Incluso los campamentos más efímeros pueden ser analizados como un lugar antropológico, porque el desmantelamiento o la destrucción de un campamento tiene como consecuencia la (necesaria) creación de otro. De hecho, a lo largo de las últimas dos décadas ha nacido toda una geografía de campamentos vinculados entre sí por procesos históricos de apropiación territorial y expulsiones.

En ciertos casos, como los pequeños campamentos autoestablecidos que encontré tras el desmantelamiento de la gran Jungla en el área urbana de la ciudad de Calais, tienen una estabilidad mínima o casi inexistente, puesto que las fuerzas policiales del esta- do francés realizaban operaciones punitivas sobre las personas migrantes de estos campamentos. Incluso estos campamentos acaban dejando una huella en el territorio, primero porque el nomadismo en una zona urbana se produce en las mismas zonas de la urbe (por ejemplo, en la historia de Calais, ha habido varios episodios en los que los migrantes aprovechan las infraestructuras arquitectónicas de la zona portuaria para resguardarse), y en segundo lugar, porque tras su marcha quedan elementos que marcan su presencia en el lugar o el signo claro de la destrucción del lugar que habían creado, como sucedió en toda la zona que había ocupado la gran Jungla (que como ya se ha señalado, había sido antaño una zona arbolada que se ha convertido en un páramo a consecuencia del uso de palas excavadoras para destruir y quitar las viviendas autoconstruidas por los migrantes).

Mientras en otras regiones y períodos históricos, como algunos ejemplos ya mencionados en Palestina o Bengala, son generaciones de personas desplazadas las que han vivido en los campamentos, la estabilidad de los campamentos surgidos en este episodio histórico llamado «la crisis de los refugiados» en Europa ha sido mucho menor en la mayoría de casos. En Grecia, Katsikas tuvo una vida efectiva de ocho meses hasta que las personas fueron trasladadas a otras acomodaciones por los peligros que suponía pasar el invierno en aquellas condiciones para sus vidas; posteriormente, se realizó una refundación del campamento, que cambió por completo su anatomía como lugar, tanto por la transformación del entorno y las construcciones, siendo las tiendas militares de lona sustituidas por viviendas prefabricadas, y por la llegada de nuevos colectivos de exiliados. El campamento de Grande-Synthe existió durante un año (aproximadamente) hasta que el incendio referido destruyó gran parte del mismo y fue evacuado y desmantelado. Sin embargo, existe una serie de campamentos que se han convertido en permanentes y no se prevé su final.

La permanencia de los campamentos como lugares antropológicos se vincula a su multiplicidad o, siendo más exactos, a la interconexión que establecen las personas que viven en distintos campamentos y cómo organizan su proyecto vital en el tránsito entre ellos. Estas conexiones no pueden explorarse al considerar los campamentos como no lugares. Algunos autores han intentado poner de manifiesto estas conexiones entre campamentos, bien señalando los efectos que han producido la red de "centros de acogida» (An- 
sems de Vries y Guild 2018; Tazzioli y Garelli 2018), o bien han puesto de relieve las estrategias de control que se ejercen a través la movilidad o de las vías y medios de transporte (Tazzioli 2017; Walters 2015). Sin embargo, la reintroducción de la perspectiva histórica que vincule estas redes y las formas de movilidad que se dan entre ellas pasa por el reconocimiento de la entidad social de los lugares que son los puntos neurálgicos de estos recorridos.

\section{CONCLUSIONES}

La consideración antropológica de los campamentos ha estado muy marcada por su definición ideal como no lugares, lugares sin Historia, donde no se producía cultura porque se carecía de unas estructuras sociales más allá de las basadas en la contractualidad solitaria, y donde se desnudaba al individuo. $\mathrm{Si}$ el debate se ha centrado más en el análisis del mecanismo por el cual se producía esta desposesión, la interiorización de los campamentos como un no lugar ha marcado las tendencias del análisis social con la consecuencia de reproducir y reforzar la existencia misma del objeto de estudio y de las dinámicas sociales que se dan en estos lugares.

En el recorrido de este artículo se propone que los campamentos empiecen a ser analizados como lugares para superar tres problemas fundamentales. El primero, para comenzar a analizar las dinámicas de representación identitaria que rodean el campamento y que acaban definiendo su formación y su existencia. El análisis de estas dinámicas desafía la homogeneidad que se impone a las personas exiliadas bajo las categorías jurídico-administrativas como refugiado, que hoy se han convertido en un referente cultural para las sociedades europeas en el debate público sobre las migraciones y el gobierno de las mismas. Pero además desafía la homogeneidad de las sociedades de recepción, desde las locales hasta las nacionales. En segundo lugar, permite poner de relevancia las dinámicas relacionales que se dan entre actores y entre distintos colectivos en la vida cotidiana de un campamento, esto es una vía alternativa para explorar la interconexión entre lógica y práctica securitaria y humanitaria, sin subsumir el uno al otro y sin reducir el análisis a una estéril oposición entre estructura (opresiva, securitaria) y agencia (humanitaria, en clave de autonomía individual). Por último, la reincorporación de la dimensión histórica como parte de la entidad de estos lugares nos permite desa- fiar la desconexión que se opera entre el pasado estas personas y su futuro, entre sujetos políticos y sujetos humanitarios. Pero también nos permite empezar a afrontar la reciente historia de los campamentos como una parte relevante de la actualidad, conectándolo no sólo como una variable dependiente del ejercicio del poder sino como el lugar del que parten y en el que se expresan estrategias de resistencia, formas nuevas de conceptualizar la pertenencia social. La Historia de los campamentos es una ventana de oportunidad a la Historia de Europa, y la historia de cada campamento es un fragmento de la propia realidad de cada región donde se encuentra.

La antropología debe afrontar una nueva forma de aproximar los campamentos, sobre todo tras las críticas internas a los efectos que ha tenido la práctica etnográfica en la producción y reproducción de los mismos. Conceptualizar el análisis de los campamentos a partir de su entidad como lugares antropológicos tiene una serie de ventajas fundamentales para la antropología. Es el momento para que, acabadas las «crisis», la antropología se gire sobre estos lugares para incluirlos en análisis más amplios, que los vinculen con procesos sociales, políticos e identitarios de mayor envergadura y no como burbujas auto-contenidas. Esta transición puede partir del ejercicio de centrar el análisis en una de las tres dimensiones precisas que definen los campamentos como lugar o en algunos de los elementos de expresión particular de estas dimensiones, como se ha presentado en el análisis etnográfico. El camino es largo y el recorrido incierto, pero debe iniciarse una redefinición del lugar del campamento en la consideración antropológica.

\section{BIBLIOGRAFÍA CITADA}

Agamben, Giorgio y Antonio Gimeno Cuspinera. 1998. Homo Sacer: el poder soberano y la nuda vida I. Valencia: PreTextos.

Agier, Michel. 2001. De nouvelles villes, les camps de réfugiés: éléments d'ethnologie urbaine. Annales de La Recherche Urbaine: 128-136.

Agier, Michel. 2012 [2008]. Managing the Undesirables: Refugee Camps and Humanitarian Government. D. Fernbach (trad.). Cambridge, UK: Polity Press.

Ansems de Vries, Leonie y Elspeth Guild. 2018. "Seeking Refuge in Europe: Spaces of Transit and the Violence of Migration Manage ment». Journal of Ethnic and Migration Studies 45(1): 1-11 Doi: <https://doi.org/10.1080/136918 3X.2018.1468308> 
Appadurai, Arjun. 1996. Modernity at Large. Cultural Dimensions of Globalization. Minneapolis: University of Minnesota Press.

Aris Escarcena, Juan Pablo. 2019. «Expulsions: The Construction of a Hostile Environment in Calais». European Journal of Migration and Law 21(2): 215-237.

Aris Escarcena, Juan Pablo. y A. Carolina Da Silva. 2019. «La condition des mineurs isolés à Calais, un état des lieux post-Jungle». En Sariette Batibonak, Jean-Fidèle Simba, y Hawa Coulibaly (eds.), Mutations dans les migrations, conflictualités dans les pratiques: 61-80. París : L’Harmattan.

Augé, Marc. 1998 [1992]. Los no lugares, espacios del anonimato: una antropología de la sobremodernidad. M. N. Mizraji (trad.). Barcelona: Gedisa.

Bosworth, Mary y Mhairi Guild. 2008. «Governing through Migration Control: Security and Citizenship in Britain». British Journal of Criminology 48(6): 703-719.

Barou, Jacques. (2014). «Integration of Immigrants in France: a Historical Perspective». Identities 21(6): 642-657.

Bauman, Zygmunt. 2003 [2000]. Modernidad líquida. M. Rosenberg y J. Arrambide Squirru (trad.). México D.F. : Fondo de Cultura Económica.

Bauman, Zygmunt. (2008). La sociedad sitiada. México D.F.: FCE - Fondo de Cultura Económica.

Ben-Yehoyada, Naor, Heath Cabot y Paul. A. Silverstein. 2020. «Introduction: Remapping Mediterranean Anthropology». History and Anthropology 31(1): 1-21.

Cabot, Heath. 2019a. "The Business of Anthropology and the European Refugee Regime». American Ethnologist 46(3): 261-275.

Cabot, Heath. 2019b. "The European Refugee Crisis and Humanitarian Citizenship in Greece». Ethnos 84(5): 747771.

Dal Lago, Alessandro. 2004. Non-persone: l'esclusione dei migranti in una società globale. Milán Feltrinelli.

De Genova, Nicholas. 2013. «Spectacles of Migrant 'Illegality': the Scene of Exclusion, the Obscene of Inclusion». Ethnic and Racial Studies 36(7): 1180-1198.

Derrida, Jacques. 2010. Seminario la bestia y el soberano. Volumen I, (2001-2002). Buenos Aires: Manantial.

Düvell, Franck. 2011. «Paths into Irregularity: the Legal and Political Construction of Irregular Migration». European Journal of Migration and Law 13(3): 275-295.

Fassin, Didier. 2007. "Humanitarianism as a Politics of Life». Public Culture 19(3): 499-520.

Flynn, Michael y Cecilia Josephine Cannon. 2009. «The Privatization of Immigration Detention: Towards a Global View». A Global Detention Project Working Papers Septiembre 2009: 1-25.

Hess, Sabine y Bernd Kasparek. 2017. «De- and Restabilising Schengen. The European Border Regime After the Summer of Migration». Cuadernos Europeos de Deusto 56: 47-78.
Hess, Sabine, Bernd Kasparek, Stefanie Kron, Mathias Rodatz, M. Schwertl y S. Sontowski. 2016. Der lange Sommer der Migration: Grenzregime III. Berlín : Assoziation A.

Hobsbawm, Eric. 1994. Historia el Siglo XX. Buenos Aires: Crítica.

Honneth, Axel (ed.). 2008. Reification: a New Look at an Old Idea. Nueva York

Ilcan, Suzan y Kim Rygiel. 2015. " "Resiliency Humanitarianism”: Responsibilizing Refugees through Humanitarian EmergencyGovernance in the Camp». International Political Sociology 9(4): 333-351.

Klepp, Silja. 2010. «A Contested Asylum System: The European Union between Refugee Protection and Border Control in the Mediterranean Sea». European Journal of Migration and Law 12: 1-21.

Malkki, Liisa. 1992. "National Geographic: The Rooting of Peoples and the Territorialization of National Identity Among Scholars and Refugees». Cultural Anthropology 7(1): 24-44.

Malkki, Liisa. 1994. "Citizens of Humanity: Internationalism and the Imagined Community of Nations». Diaspora: $A$ Journal of Transnational Studies 3(1): 41-68.

Malkki, Liisa. 1996. «Speechless Emissaries: Refugees, Humanitarianism, and Dehistoricization». Cultural Anthropology 11(3): 377-404.

Mezzadra, Sandro. y Brett Neilson. 2017. La frontera como método o la multiplicación del trabajo. Madrid: Traficantes de Sueños.

Pallister-Wilkins, Polly. 2015. «The Humanitarian Politics of European Border Policing: Frontex and Border Police in Evros». International Political Sociology 9(11): 53-69.

Rahola, Federico. 2003. Zone definitivamente temporanee. I luoghi dell'umanità in ecceso. Milán Ombre corte.

Rahola, Federico. 2006. "On the Victim's Side: A Note on Humanitarianism in the Time of Wars of Interference. Ephemera». Theory \& Politics in Organization 6(1): 40-56.

Rahola, Federico. 2007. «La forme-camp. Pour une généalogie des lieux de transit et d'internement du présent». Cultures \& Conflits $68: 31-50$

Recchi, Ettore. 2015. Mobile Europe. The Theory and Practice of Free Movement in the EU. London : Palgrave Macmillan.

Rozakou, Katerina. 2019. “'How did you Get in?” Research Access and Sovereign Power During the 'Migration Crisis' in Greece». Social Anthropology 27(S1): 68-83.

Rygiel, Kim. 2011. «Bordering Solidarities: Migrant Activism and the Politics of Movement and Camps at Calais». Citizenship Studies 15(1): 1-19.

Rygiel, Kim. 2016. «Dying to Live: Migrant Deaths and Citizenship Politics along European Borders: Transgressions, Disruptions, and Mobilizations». Citizenship Studies 20(5): 545-560.

Sandri, Elisa. 2018. “'Volunteer Humanitarianism”: Volunteers snd Humanitarian Aid in the Jungle Refugee Camp of Calais». Journal of Ethnic and Migration Studies 44(1): 65-80. 
Sassen, Saskia. 2013 [1999]. Inmigrantes y ciudadanos. De las migraciones masivas a la Europa Fortaleza. J. Alborés Rey (trad.). Madrid: Siglo XXI.

Schwenken, Helen. 2014. "From Sangatte to 'The Jungle': Europe's Contested Borderlands». En H. Schwenken y S. Ruß-Sattar (eds.), New Border and Citizenship Politics: 171186. Londres: Palgrave Macmillan UK.

Stavenhagen, Rodolfo. 2000. Conflictos étnicos y estado nacional. México D.F.: Siglo XXI.

Stierl, Maurice. 2016. "A Sea of Struggle - Activist Border Interventions in The Mediterranean Sea». Citizenship Studies 20(5): 561-578.

Stierl, Maurice. 2018. "A Fleet of Mediterranean Border Humanitarians». Antipode 50(3): 704-724.

Tazzioli, Martina. 2017. «Containment Through Mobility: Migrants' Spatial Disobediences and the Reshaping of Control Through the Hotspot System ". Journal of Ethnic and Migration Studies 44:1-16. Doi: http://doi.org.10.1080/136 9183X.2017.1401514>.

Tazzioli, Martina. y Glenda Garelli. 2018. «Containment Beyond Detention: the Hotspot System and Disrupted Migration Movements across Europe». Environment and Planning. D: Society and Space 0: 1-19. Doi: <https://doi. org/10.1177/0263775818759335>.

Ticktin, Miriam. 2005. «Policing and Humanitarianism in France: Immigration and the Turn to Law as State of Exception». Interventions 7(3): 346-368.

Ticktin, Miriam. 2014. «Transnational Humanitarianism». Annual Review of Anthropology 43(1): 273-289.
Ticktin, Miriam. 2016. "Thinking Beyond Humanitarian Borders». Social Research: An International Quaterly 83(2): 255-271.

Tsianos, Vasilis y Serhat Karakayali. 2010. «Transnational Migration and the Emergence of the European Border Regime: An Ethnographic Analysis». European Journal of Social Theory 13(3): 373-387.

Tutton, Richard, Christine Hauskeller y Steve Sturdy. 2014. "Suspect Technologies: Forensic Testing of Asylum Seekers at the UK Border». Ethnic and Racial Studies 37(5): 738-752.

Van Baar, Huub. 2014. "The Centripetal Dimension of the EU's External Border Regime». Etnofoor 26(2): 87-93.

Vertovec, Steven y Robin Cohen (eds.). 1999. Migration, Diasporas and Transnationalism. Cheltenham: Elgar.

Wacquant, Loic. 2014. «Marginality, Ethnicity and Penality in the Neo-Liberal City: an Analytic Cartography». Ethnic and Racial Studies 37(10): 1687-1711.

Walters, William. 2006. «Border/Control». European Journal of Social Theory 9(2): 187-203.

Walters, William. «Foucault and Frontiers: Notes on the Birth of the Humanitarian Border». En U. Bröckling, S. Krasmann y T. Lemke (eds.), Governmentality: Current Issues and Future Challenges: 138-164. Nueva Yorl: Routledge.

Walters, William. 2015. «Migration, Vehicles and Politics: Three Theses on Viapolitics». European Journal of Social Theory 18(4): 469-488.

Williams, Jill M. 2015. «From Humanitarian Exceptionalism to Contingent Care: Care and Enforcement at the Humanitarian Border». Political Geography 47 (2015): 11-20. 